\title{
Florence Naugrette, Le théâtre de Victor Hugo
}

\section{Valentina Ponzetto}

\section{(2) OpenEdition}

\section{Journals}

\section{Édition électronique}

URL : https://journals.openedition.org/studifrancesi/21451

DOI : 10.4000/studifrancesi.21451

ISSN : 2427-5856

\section{Éditeur}

Rosenberg \& Sellier

\section{Édition imprimée}

Date de publication : 1 décembre 2019

Pagination : 590

ISSN : 0039-2944

\section{Référence électronique}

Valentina Ponzetto, «Florence Naugrette, Le théâtre de Victor Hugo », Studi Francesi [En ligne], 189 (LXIII | III) | 2019, mis en ligne le 01 mars 2020, consulté le 11 novembre 2021. URL : http://

journals.openedition.org/studifrancesi/21451; DOI : https://doi.org/10.4000/studifrancesi.21451

Ce document a été généré automatiquement le 11 novembre 2021.

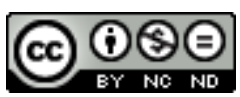

Studi Francesi è distribuita con Licenza Creative Commons Attribuzione - Non commerciale - Non opere derivate 4.0 Internazionale. 


\title{
Florence Naugrette, Le théâtre de Victor Hugo
}

\author{
Valentina Ponzetto
}

\section{RÉFÉRENCE}

Florence Naugrette, Le théâtre de Victor Hugo, Lausanne, Ides et Calendes, 2016, 111 pp.

1 Sorti en 2016, revenu sur le devant de la scène cette année avec l'inscription d'Hernani et Ruy Blas au bac, ce petit volume s'impose d'ores et déjà comme un classique et un incontournable pour quiconque désire mieux connaître le théâtre de Victor Hugo: étudiants, chercheurs ou simples lecteurs curieux. Dû à la plume de Florence Naugrette, la plus grande spécialiste actuelle du théâtre hugolien, cet ouvrage réussit en effet le défi d'être à la fois simple, clair et concis, respectant le format agile d'une centaine de pages de la collection qui compte à ce jour une quinzaine de titres, sans jamais tomber dans la simplification, écueil redoutable avec un auteur comme Hugo aussi connu que sujet aux clichés faciles.

2 L'ouvrage s'organise en deux parties. Une première, historique, retrace «La Vie théâtrale de Victor Hugo», subdivisée en périodes marquantes: «L'enfance de l'art théâtral», des premiers essais d'un écolier de dix ans jusqu'en 1827, année de Cromwell et de sa célèbre préface; la période houleuse de 1828-1830, qui de la chute d'Amy Robsart et de la censure de Marion Delorme à la retentissante bataille d'Hernani voit Hugo et ses confrères romantiques «à la conquête des grandes scènes officielles». Puis la période foisonnante des années 1830, qui voit se multiplier les scandales mais aussi les triomphes entre la Comédie-Française, la Porte-Saint-Martin et le nouveau Théâtre de la Renaissance, inauguré en 1838 avec «l'apothéose» de Ruy Blas, suivie de la déception des Burgraves (1843), dont la réception froide et mitigée a trop souvent été qualifiée de «chute». Enfin, par-delà le hiatus de l'exil et des longues années consacrées plutôt à la poésie et aux romans, la «seconde carrière théâtrale» hugolienne, avec le retour sur les scènes parisiennes et l'écriture inventive et surprenante du Théâtre en liberté. 
3 Pour chaque étape marquante Florence Naugrette prend soin de rappeler sa signification et son importance dans l'évolution de la pensée hugolienne, mais aussi de balayer les fausses idées reçues, par exemple en ramenant à leurs justes proportions la portée de la préface de Cromwell («aucun dramaturge romantique ne s'est jamais explicitement revendiqué de cette préface», p. 11) ou, inversement, de la réception des Brugraves. En filigrane se dessine une relecture critique du romantisme théâtral que l'A. mène depuis des années dans ses différents travaux. «Les manuels», écrit-elle ici, «montent en épingle les deux dates phares de la très métaphorique «bataille» d'Hernani et de l'arrêt (momentané) de la production théâtrale hugolienne pour restreindre le Romantisme en France à la période étroite de 1830 à 1843. Alors que le romantisme, contemporain en France à bien d'autres mouvements, ou tendances qu'il n'a pas détrônées, et qui ne l'ont pas davantage détrôné en retour, a commencé bien avant Hugo, et s'est poursuivi bien après Les Burgraves» (p. 32).

4 Une même volonté d'éclaircissement et de relecture critique des traits fondamentaux $\mathrm{du}$ théâtre hugolien sous-tend la seconde partie, «le théâtre, point d'optique», consacrée à l'analyse des œuvres et articulée en trois points forts et autant de chapitres. D'abord un retour sur la conception du «mélange des genres» (pp. 51-67), à relativiser aussi bien par rapport à l'histoire littéraire et à la permanence de traditions consacrées que par rapport aux différents personnages et aux œuvres successives de Victor Hugo lui-même. Que nos étudiants et certains metteurs en scène se le tiennent pour dit: il serait absurde de vouloir chercher dans chaque situation et dans chaque personnage un mélange obligatoire de grotesque et de sublime. Ensuite un chapitre sur «l'écriture scénique» (pp.67-86) rappelant par exemple l'importance des espaces conçus comme des pièges qui se renferment sur les héros et contribuent à l'évolution de l'intrigue, des accessoires emblématiques, ou de l'interprétation des uns et des autres par des metteurs en scènes et des scénographes marquants comme Vilar, Vitez, Benno Besson, Brigitte Jacques, Yannis Kokkos ou Ezio Toffolutti. Enfin un aperçu de la pensée politique et sociale qui émerge du théâtre de Hugo («Un théâtre pensif», pp. 86-96), entre «mise en cause de la peine de mort appliquée au nom de la raison d'État» (p. 87), dénonciation de la violence politique des puissants comme de la foule aveugle, réflexions visionnaires de quelques "grands hommes» magnifiés, tels Cromwell ou Charles-Quint, et utopie tardive, inscrite au cœur du Théâtre en liberté, d'une «puissance des faibles», qui, face «à la tyrannie, aux préjugés sociaux, aux séductions du dieu Argent» seraient forts «de la seule valeur qui n'a pas de prix, l'amour, dans toute son étendue»: conjugal, charnel, filial, pour son prochain, pour la Nature, pour la Patrie et la Liberté (p. 94).

5 Les notes de bas de page et la respective bibliographie en fin de volume, certes «sélective» mais choisie avec le plus grand soin, renvoient tour à tour les lecteurs plus exigeants aux études approfondies des meilleurs spécialistes de Victor Hugo et du théâtre romantique: Arnaud Laster, Jean-Marc Hovasse, Olivier Bara, Sylvain Ledda et bien entendu Florence Naugrette elle-même, qui avec ce petit volume donne une clé d'entrée efficace à une large partie de sa production scientifique ainsi qu'au théâtre hugolien. 